\title{
Exchange Rate Expectations, Unbiasedness and Central Bank Intervention: The Experience of the Southern Cone
}

Gonzalo Varela*

The World Bank and the University of Sussex, 1818 H Street, Mail Stop MC-3 409, Washington DC, USA

\begin{abstract}
This paper uses new survey data on foreign exchange expectations for Argentina, Brazil and Uruguay to test the hypothesis of unbiasedness. The pattern emerging is revealing: only Argentinean forecasts are unbiased predictors of exchange rate movements, while agents err systematically for Brazil and Uruguay. We argue that the systematic intervention of the Argentinean Central Bank in the foreign exchange market is likely to explain this result, as it simplifies the forecast exercise in that market. As long as the requirements to predict well are simple, agents perform well. If instead the exchange rate determination model is intricate, expectation failures arise.
\end{abstract}

Keywords: Exchange rate expectations; Foreign exchange interventions; Developing countries

\section{Introduction}

In a recent contribution, Frankel and Poonawala [1] show that forward markets in emerging currencies are less biased than in major ones. The authors conjecture that as relatively high inflation has been pervasive in emerging economies, exchange rate trends are more easily identifiable; hence, the ability to predict is better.

Here we exploit available survey data on exchange rate expectations for Argentina, Brazil and Uruguay and test the unbiasedness hypothesis for the currencies of these Southern Cone countries. Looking at the performance of forecasts for these foreign exchange markets is revealing as they share some characteristics. Price inflation records in the last decade have been low by historical standards. In fact, over 2005-2009, the annual variation of the CPI was below $10 \%$ in almost all cases, for the three countries (Table 4$)^{1}$. In addition, these are countries with a history of substantial Central Bank's intervention in foreign exchange markets, generally taking the form of preannounced paths for currency prices. It was only recently that Central Banks (CBs) stopped announcing a target for them, in a movement toward floating regimes (Argentina in 2002, Brazil in 1999, Uruguay in 2002). De jure, freely floating regimes are in place in the three countries, although whether the regimes are freely floating the facto is less clear. Rather, the three foreign exchange markets are consistent with managed floating regimes, but the degrees of interventions of CBs vary substantially across countries, which allow us to explore their role in expectations' unbiasedness.

Two regularities in the literature motivate this paper. First, that most of the tests on unbiasedness of exchange rate expectations have been applied to major currencies and developed economies. The exceptions are the works of Bansal and Dahlquist [2] and Frankel and Poonawala [1] that pool together developed and developing economies' markets, and Gilmore and Hayashi [3] that focuses on emerging economies only. In all of these cases, the biases found in forecasts for developing countries' currencies are smaller than those found in forecasts for developed countries' currencies. Second, that the literature does not answer the follow-up question on the drivers of that difference between forecasts for developing and developed economies' currencies. This paper contributes to the literature by focusing on three

${ }^{1}$ The exception is Argentina in 2006, with CPI inflation at $10.9 \%$. Note that for the case of Argentina, there is a consensus on the bias of the official estimates for inflation with private analysts estimating CPI inflation at levels well above those reported by the National Statistics Office. developing countries' currency markets. It investigates the extent to which survey-based expectations are unbiased predictors of ex-post exchange rate changes, and explores the role of CBs intervention in the forecast bias heterogeneity.

\section{How Much Central Bank Intervention?}

To measure the extent to which CBs intervene in foreign exchange markets we follow Calvo and Reinhart [4] approach. These authors construct a number of indicators that allow them to measure the degree of CBs' intervention in foreign exchange markets that consists in examining the frequency distribution of changes in the nominal exchange rate depreciation, rates of change of foreign exchange reserves, and rates of change of the monetary base. If the regime implies substantial CB intervention, the authors expect to find minimal changes in depreciation rates, and substantial changes in the rates of change of foreign exchange reserves and of the monetary base, and the converse, when the regime is a freely floating one. Their benchmark for comparison is the USA, where, according to the authors, the regime is closest to a freely floating one.

For the countries of interest, Pires de Souza [5] also uses Calvo and Reinhart [4] approach and concludes, for the period post-crisis (20002005), that while in Brazil and Uruguay the regimes were closer to a freely floating one, the Argentinean was closer to a peg in disguise. The author argues that while in the former two countries, CBs intervene to avoid 'excessive' volatility, in Argentina, intervention had two goals: to reduce the burden of the debt and to keep a 'competitive exchange rate'.

The analysis of Pires de Souza [5] does not cover the whole period under analysis (2005-2010). To gain an understanding of the heterogeneous behavior of $\mathrm{CBs}$ in the different markets under

*Corresponding author: Gonzalo Varela, The World Bank, and the University of Sussex, 1818 H Street, Mail Stop MC-3 409, Washington DC-20433, USA, Tel: +1 202779 5544; E-mail: gonzalo.j.varela@googlemail.com

Received January 31, 2014; Accepted March 19, 2014; Published March 27 2014

Citation: Varela G (2014) Exchange Rate Expectations, Unbiasedness and Central Bank Intervention: The Experience of the Southern Cone. J Glob Econ 2: 110. doi: $10.4172 / 2375-4389.1000110$

Copyright: (C) 2014 Varela G. This is an open-access article distributed under the terms of the Creative Commons Attribution License, which permits unrestricted use, distribution, and reproduction in any medium, provided the original author and source are credited. 
consideration, we calculated Calvo and Reinhart [4] indicators for each of the three countries. Of course, these measures are imperfect indicators of CBs' intervention. If, for example, the economies are subject to idiosyncratic shocks, exchange rates, reserves, and monetary base variability will differ independently of any policy decision of a CB. During the period considered, one of the largest shocks that could have affected foreign exchange markets in these economies was related to positive terms of trade, arising from increases in world food prices. Given the production structure of the economies, this shock is likely to have been common to the three ${ }^{2}$. Indeed, the terms of trade of the three countries, measured in US dollars, show, although with different slopes, an upward trend during the period. As a consequence, their trade and current account balances are highly correlated. Table 1 shows the correlation coefficients for the Current Account/GDP and the Trade Balance/GDP for the three countries. Taking the trade balance/GDP, it is possible to see signs of strong co-movements. The correlation between the trade balance/GDP between Argentina and Uruguay is of $74 \%$, between Argentina and Brazil of 54\%, while for Brazil and Uruguay of $69 \%$.

For these reasons we consider these indicators to be acceptable measures of intervention. However, the interpretation of the indicators reported here should be done with caution, acknowledging their limitations to accurately assess the differences in the degree of $\mathrm{CB}$ intervention across countries.

Table 2 reports the frequency with which depreciation rates, rates of change of foreign exchange reserves of the Central Bank, and rates of change of the monetary base, fell outside: (a) a band given by 1

\begin{tabular}{|c|c|c|c|c|c|c|c|}
\hline \multicolumn{3}{|c|}{ Current Account/GDP } & & \multicolumn{3}{|c|}{ Trade Balance/GDP } & \\
\hline & Argentina & Brazil & Uruguay & & Argentina & Brazil & Uruguay \\
\hline \multicolumn{2}{|c|}{ Argentina } & & & \multicolumn{2}{|c|}{ Argentina } & & \\
\hline Brazil & 0.8099 & & & Brazil & 0.5435 & & \\
\hline Uruguay & 0.4847 & 0.6507 & & Uruguay & 0.7407 & 0.6925 & \\
\hline
\end{tabular}

Source: Own elaboration based on data from World Development Indicators.

Table 1: Correlation Coefficients for Current Account Balance/GDP and Trade Balance/GDP (2004-2012).

\begin{tabular}{|c|c|c|c|c|c|c|}
\hline & \multicolumn{2}{|c|}{ Argentina } & \multicolumn{2}{c|}{ Brazil } & \multicolumn{2}{c|}{ Uruguay } \\
\hline & $1 p p$ Band & $\begin{array}{l}2.5 p p \\
\text { Band }\end{array}$ & 1pp Band & $\begin{array}{c}2.5 p p \\
\text { Band }\end{array}$ & 1pp Band & $2.5 p p$ Band \\
\hline Dep. NER & 0.24 & 0.08 & 0.77 & 0.45 & 0.56 & 0.21 \\
\hline$\Delta$ Reserves & 0.76 & 0.55 & 0.83 & 0.53 & 0.88 & 0.61 \\
\hline$\Delta$ Mon. Base & 0.85 & 0.52 & 0.73 & 0.44 & 0.85 & 0.71 \\
\hline
\end{tabular}

Source: Own elaboration using IMF IFS data. The period considered is Jan 2005July 2010. Dep. NER stand for nominal exchange rate depreciation, $1 \mathrm{pp}$ and $2.5 \mathrm{pp}$ stand for 1 and 2.5 percentage points of amplitude bands.

Table 2: Adaptation of Calvo and Reinhart (2000)'s Fear of Floating Indicators.

${ }^{2}$ Another important and common shock to the three economies was the swing in the international value of the dollar during the period under consideration.

${ }^{3}$ The gaps are due to the fact that for some months, the dataset only contains forecasts over shorter or longer horizons than the one-month type analysed in this paper.

${ }^{4}$ Further information can be found at the website of the BCRA: http://www.bcra. gov.ar.

${ }^{5}$ Further information can be found at the website of the BCB: https://www3.bcb. gov.br.

${ }^{6}$ More recently, however, the $\mathrm{BCU}$ has started disclosing the micro data. These were not available at the moment of writing this paper. Further information can be found at the website of the BCU: http://www.bcu.gub.uy. percentage point amplitude, and (b) a band given by 2.5 percentage points amplitude. The striking result corresponds to the substantial differences in terms of the frequency distributions for nominal exchange rate depreciations. While in Argentina only $24 \%$ of the monthly changes in the variable fell outside the interval $(-1 \%,+1 \%)$ and $8 \%$ fell outside the interval $(-2.5 \%,+2.5 \%)$, in Brazil and Uruguay monthly depreciation rates greater than $1 \%$ in absolute value tended to be the rule rather than the exception. These results are in line with the finding of Pires de Souza [5] for the preceding period (2000-2005). Brazil and Uruguay's variations in depreciation rates are more in line with a freely floating regime, whereas Argentina's variations are more in line with a peg in disguise. The indicators that refer to the frequency distribution of the rates of change of CB's reserves and that of the Monetary Base do not suggest substantial differences. One could conclude, thus, that even though intervention is present in the three markets - hence the substantial variation in reserves for the three cases - in Argentina it is associated with much less exchange rate flexibility.

\section{Estimation Strategy and Results}

\section{The data}

This section exploits monthly survey data on exchange rate expectations, for a forecast horizon of one month for Argentina (from November 2004 to July 2010 - with gaps) ${ }^{3}$, for Brazil (from January 2002 to July 2010), and for Uruguay (from June 2005 to July 2010).

For Argentina, data were obtained from the Argentinean Central Bank (BCRA). The BCRA collects expectations data for exchange rates through the "Market Expectations Monitoring System". Participation in the survey is voluntary and confidential. The BCRA only discloses summary measures (average, median and standard deviations) of the forecasts. The number of participants in the survey is unknown to us ${ }^{4}$.

For Brazil, data were obtained from the Brazilian Central Bank (BCB). The BCB collects survey data on expectations for the exchange rate through the "System of Market Expectations" (SME). Approximately 88 institutions send their forecasts to the SME, including banks, asset managers and stock brokers, consulting firms, non-financial enterprises and pension funds. Participants that are 'active' in responding to the $\mathrm{BCB}$ questionnaires are kept in the system, although no definition of 'active' is given by the BCB. Only summary measures are disclosed (mean, median, coefficient of variation, standard deviation, maximum and minimum $)^{5}$.

For Uruguay, data were obtained from the Central Bank of Uruguay (BCU). The BCU surveys about 16 analysts from banks, universities, and private enterprises. Only summary measures are disclosed (mean, median, standard deviation, minimum and maximum $)^{6}$.

Actual exchange rates (average of the period, expressed in domestic currency per dollar), variations of foreign exchange reserves, and inflation rates were obtained from the IMF IFS database.

\section{Unbiasedness Hypothesis: Estimation and Results}

To test for unbiasedness of expectations for the three countries, we estimate equation (1):

$$
\Delta S_{i, t+k}=\alpha_{i}+\beta_{i} \Delta S_{i, t+k}^{e}+e_{i, t+k}
$$

Where $\Delta S_{i, t+k}$ is the actual depreciation of country i, from period 
$\mathrm{t}$ to period $\mathrm{t}+\mathrm{k}, \Delta S_{i, t+k}^{e}$ is the expected depreciation for country $\mathrm{i}$, at time $\mathrm{t}$, for the period $\mathrm{t}-\mathrm{t}+\mathrm{k}$, e is an error term assumed orthogonal to expected depreciation, serially un-correlated and homoscedastic, and alpha and beta are parameters.

The test for unbiasedness of expectations is a joint test $\beta_{i}=1$ and $\alpha_{i}=0$. This simple proposition of unbiasedness has been almost systematically rejected in the past when the focus was placed on major currencies $[6,7]^{7}$.

One could estimate separate equations for each country using OLS, the best linear unbiased estimator under the assumptions placed on the error term. However, gains in precision due to a larger sample size could be achieved if we stack the data together and estimate a system as in equation (2):

$$
\left[\begin{array}{l}
\Delta s_{1} \\
\Delta s_{2} \\
\Delta s_{3}
\end{array}\right]=\left[\begin{array}{ccc}
\Delta s_{1}{ }_{1} & 0 & 0 \\
0 & \Delta s_{2}{ }_{2} 0 \\
0 & 0 & \Delta s_{3}{ }^{e}
\end{array}\right]\left[\begin{array}{l}
\beta_{1} \\
\beta_{2} \\
\beta_{3}
\end{array}\right]+\left[\begin{array}{l}
\varepsilon_{1} \\
\varepsilon_{2} \\
\varepsilon_{3}
\end{array}\right]=X \beta+\varepsilon
$$

Where $\Delta S_{i}$ is an $n \times 1$ vector containing depreciation rates for the i-th country, $\Delta s_{i}^{e}$ is a matrix of dimensions nx2, containing a first column of ones, and a second column of expected depreciation rates for the $\mathrm{i}$-th country over $\mathrm{n}$ periods, $\beta_{i}$ is a $2 \mathrm{x} 1$ vector of parameters (alpha and beta), and $\mathcal{E}_{i}$ is an nxl vector of errors.

Estimating equation 2 using OLS yields inefficient estimates even assuming serially uncorrelated, and homoscedastic errors within the i-th equation because error contemporaneous correlations across equations are likely to be non-zero. Since the three exchange rates considered are defined with respect to the US dollar, unanticipated shocks affecting the international value of the dollar, for example, will

${ }^{7}$ See Mac Donald (2000) and Jongen et al. (2008) for reviews on the subject.

${ }^{8}$ For a detailed exposition of SURE techniques, see Greene (2002), Chapter 14. appear in the error term, generating cross-sectional dependence. The literature deals with this by using Seemingly Unrelated Regression Techniques (SURE), due to Zellner [8]. The SURE estimator is a Generalized Least Squares Estimator (GLS) in which the weighting matrix, $\Omega$ is defined as the Kronecker product of the error covariance matrix of the system of equation (2), $\sum$, and an identity matrix I. The GLS estimator of the parameters $\beta_{i}$ is given by:

$$
\widehat{\beta}=\left[X ! \Omega^{-1} X\right]^{-1} X^{\prime} \Omega^{-1} y
$$

The choice of whether to estimate separate equations by country or use seemingly unrelated regression techniques and estimate as in (2) is not obvious. This is because the three datasets only overlap over a period of 30 observations. For Brazil, data are available since January 2002, until July 2010, for Uruguay between June 2005 and July 2010; for Argentina from November 2004 until July 2010 with gaps. Using SURE would imply throwing away the non-overlapping part of the data. For this reason we estimate the system of seemingly unrelated regressions, as in 2 and test for unbiasedness on the overlapping 30 periods. Then we estimate equation 1 and test unbiasedness separately for each country. Thus, we exploit all information.

Given that data are monthly and expectations are formed over onemonth horizons, we assume that the non-invertible moving average process typically present in the error term of these types of models is not present. However, even with non-overlapping observations, serial correlation may still be a problem, yielding biased standard errors. For this reason, as a robustness check, we also estimate the equations separately, country by country, using GMM with the Newey and West [10] adjustment.

Scatter plots of the data on actual and expected depreciation for each of the countries considered along with a 45-degree line are displayed in Figures 1-3. Results of estimating (2) for Uruguay and Brazil only, and then for Uruguay, Brazil and Argentina are reported in columns 1 and 2 of Table 2, along with the unbiasedness tests and some diagnostic statistics. Results of estimating (1) separately for every country are reported in Table 3.

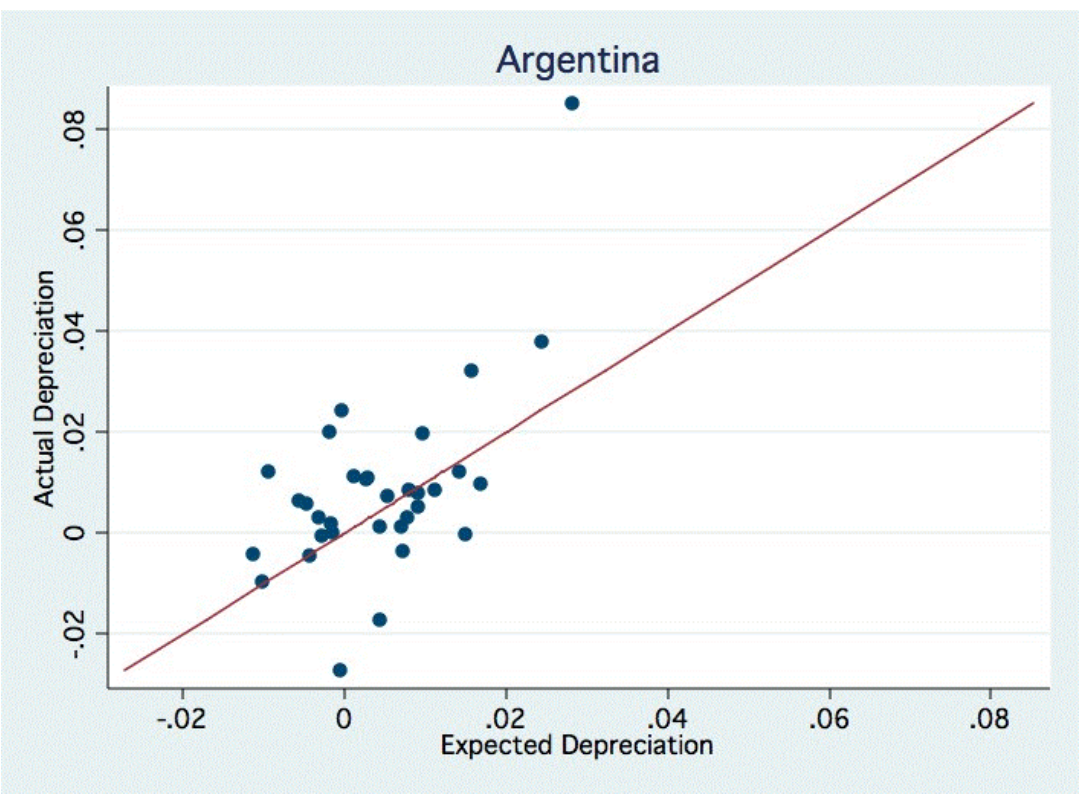

Figure 1: Scatter of Expected and Actual Depreciation Rates: Argentina. 


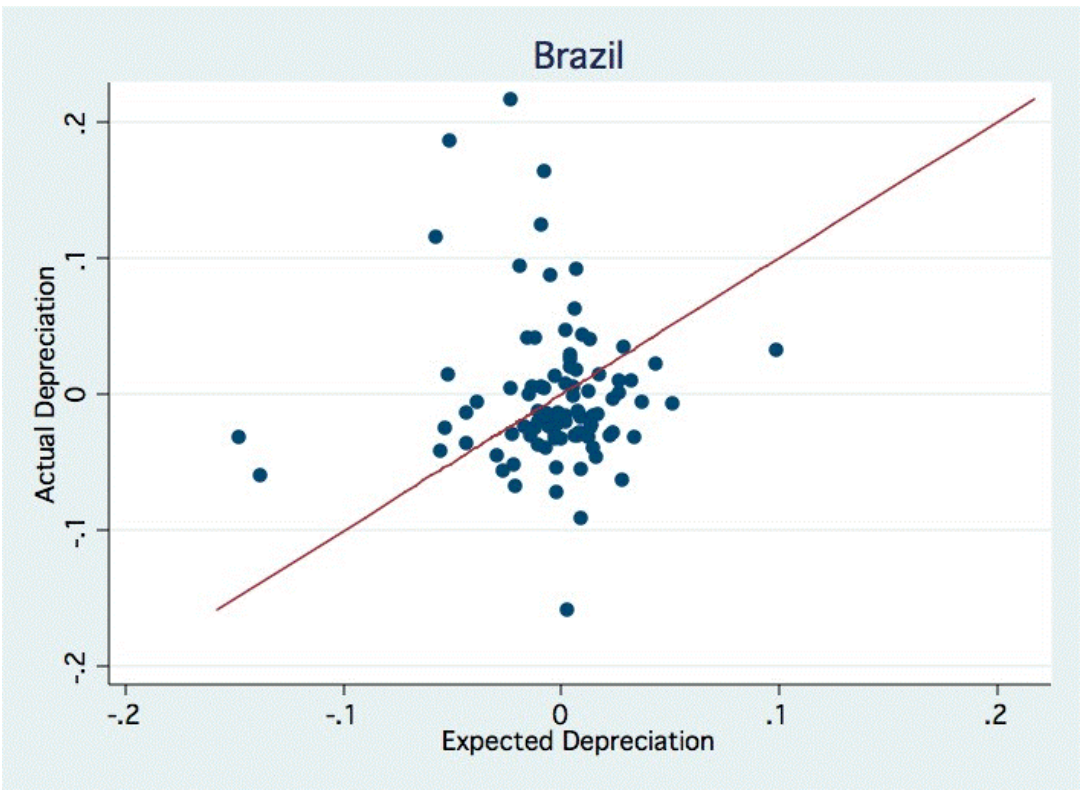

Figure 2: Scatter of Expected and Actual Depreciation Rates: Brazil.

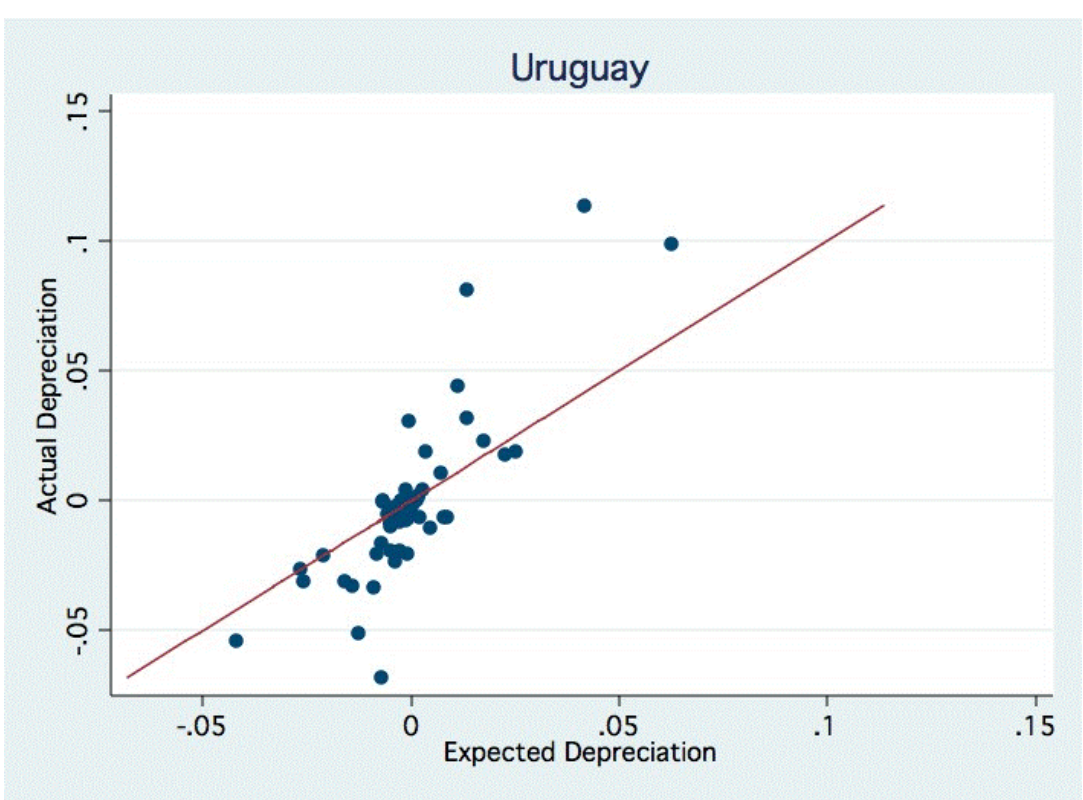

Figure 3: Scatter of Expected and Actual Depreciation Rates: Uruguay.

We focus first on the results when cross-sectional dependence is controlled for (SURE estimator, equation (2), in Table 3). The first point to be made is that the null of independence of errors across equations, tested using the Breusch-Pagan test of cross sectional independence (B-P Indep.) is clearly rejected, confirming that SURE were necessary to treat the cross sectional dependence. Second, both when stacking the models for Brazil and Uruguay (column 1) and stacking the models for Brazil, Uruguay and Argentina (column 2), we observe that agents in Uruguay predict the sign of the exchange

${ }^{9}$ For the sake of brevity of exposition we do not report the results, but the unbiasedness hypothesis is also rejected when estimating the model for Uruguay and Brazil only (column 1 of Table 1). P-values are 0.0175 and 0.0021 . rate movement right, but under-predict its movement. For Brazil, the co-efficient on expectations is statistically insignificant, and, when the three country models are stacked up together, even the predicted sign is in the opposite direction of the actual change. The null hypothesis of unbiasedness of expectations is rejected by the data at $5 \%$ significance for both countries as suggested by the F-statistics being greater than the critical value 9 . In Argentina, instead where the Central Bank intervened actively and systematically during the period to keep a 'competitive' exchange rate, unbiasedness of expectations cannot be rejected, even at $10 \%$ significance.

The results of estimating separate models by country are reported in Table 4 . The results are analogous to those obtained using seemingly 


\begin{tabular}{|c|c|c|c|c|c|c|}
\hline \multirow[b]{2}{*}{ Dep. Var. } & \multicolumn{2}{|c|}{ (1) 1-M Uru-Bra } & \multirow[b]{2}{*}{ Diag. } & \multicolumn{2}{|c|}{ (2) 1-M Uru-Bra-Arg } & \multirow[b]{2}{*}{ Diag. } \\
\hline & Coef. & S.E. & & Coef. & S.E. & \\
\hline \multicolumn{7}{|l|}{ Actual depreciation } \\
\hline \multicolumn{7}{|c|}{ Uruguay } \\
\hline Expected Depreciation & $1.55^{* * *}$ & -0.14 & RMSE: 0.017 & $1.57^{* \star *}$ & -0.18 & RMSE: 0.022 \\
\hline Constant & 0.0009 & 0 & $\mathrm{R} 2=0.7038$ & -0.0009 & 0 & F Unbias $=5.24$ \\
\hline \multicolumn{7}{|c|}{ Brazil } \\
\hline Expected Depreciation & 0.09 & -0.29 & RMSE: 0.048 & -0.16 & -0.44 & RMSE: 0.055 \\
\hline Constant & -0.001 & -0.01 & $R 2=-0.0036$ & -0.01 & -0.01 & F Unbias $=3.46$ \\
\hline \multicolumn{7}{|c|}{ Argentina } \\
\hline Expected Depreciation & & & & $1.26^{* * *}$ & -0.24 & RMSE: 0.015 \\
\hline Constant & & & & 0.001 & 0 & F Unbias. $=1.37$ \\
\hline Observations & 54 & & & 30 & & \\
\hline $\mathrm{AIC}$ & -474.05 & & & -423.75 & & \\
\hline $\mathrm{BIC}$ & -466.09 & & & -415.34 & & \\
\hline B-P Indep & 9.999 & & & 21.999 & & \\
\hline
\end{tabular}

Notes: Standard errors in parentheses, ${ }^{*}(p<0.10),{ }^{* *}(p<0.05),{ }^{* * *}(p<0.01)$, B-P Indep is the Breusch Pagan test of cross-sectional independence. B-P is distributed chi squared $\mathrm{j}(\mathrm{j}=$ number of countries). $\mathrm{CV}$ at $5 \%$ for chi sq $(2)=5.99$, for chi sq $(3)=7.81 . \mathrm{F}$ test of unbiasedness is a joint test for alpha=0 and beta $=1, \mathrm{~F}$ is distributed $\mathrm{F}(2,84)$ $\mathrm{CV}$ at $5 \%=3.1$, at $10 \%=2.34$

Table 3: Unbiasedness Tests for Argentina, Brazil and Uruguay (SURE estimator).

\begin{tabular}{|c|c|c|c|c|c|c|}
\hline \multirow[b]{2}{*}{ Dep. Var. } & \multicolumn{2}{|c|}{ Brazil } & \multicolumn{2}{|c|}{ Argentina } & \multicolumn{2}{|c|}{ Uruguay } \\
\hline & Coef. & S.E. & Coef. & S.E. & Coef. & S.E. \\
\hline \multicolumn{7}{|l|}{ Actual Depreciation } \\
\hline Expected Depreciation & -0.03 & -0.18 & $1.20^{\star \star \star}$ & -0.28 & $1.68^{* * *}$ & -0.21 \\
\hline Constant & 0 & -0.01 & 0 & 0 & 0 & 0 \\
\hline Observations & 93 & & 33 & & 62 & \\
\hline F Unbiasedness & 16.1 & & 1.5 & & 21.7 & \\
\hline $\mathrm{AIC}$ & -273.73 & & -181.52 & & -328.37 & \\
\hline $\mathrm{BIC}$ & -268.67 & & -178.53 & & -324.12 & \\
\hline
\end{tabular}

Notes: Standard errors in parentheses, ${ }^{*}(p<0.10),{ }^{* *}(p<0.05),{ }^{* * *}(p<0.01), F$ Unbias is a test on alpha=0 and beta=1. $C V$ for $B r a z i l ~ F(2,91)=3.09 . F o r$ Arg. $F(2,31)=3.3$ For Uru. $\mathrm{F}(2,60)=3.15$

Table 4: Unbiasedness Tests for Argentina, Brazil and Uruguay (GMM - Newey-West estimator).

unrelated regression methods. While data for Brazil and Uruguay suggest that agents fail at predicting the path of the exchange rate depreciations (in Uruguay they under-predict it, while in Brazil they do not even get the sign right), data for Argentina upheld the notion of unbiasedness of exchange rate depreciation expectations already presented before.

A likely explanation is that the systematic intervention of the Central Bank and implicit commitment to keep a competitive exchange rate may simplify the forecast process. This is consistent with a very intuitive message: as long as what it takes to predict well is simple, agents perform well. If instead the exchange rate determination model is intricate or unfamiliar, agents fail at predicting.

\section{Conclusions}

This paper used survey data for the Argentinean, Brazilian and Uruguayan foreign exchange rate markets and tested for expectation unbiasedness. Given that the Uruguayan and Argentinean Peso, and the Brazilian Real were floated to different extents, around the beginning of the 2000s, and that the three countries have exhibited relatively low levels of inflation since then, it is interesting to test for expectation failures in the three markets and investigate whether some pattern can be extracted.

For the Argentinean Peso/Dollar market, where the Argentinean Central Bank intervention is substantial and rather systematic, we found that unbiasedness of expectations cannot be rejected. Instead, unbiasedness is clearly rejected for the Brazilian and the Uruguayan markets.

The patterns that emerged from these results add to the recent contribution of Frankel and Poonawala [1], and hint that systematic $\mathrm{CB}$ intervention, even if it does not involve a public announcement or a commitment to a particular exchange rate value, may simplify the forecast exercise for the participants in the foreign exchange market. Further to this, the evidence presented here on significant expectation failures does not necessarily imply irrationality, but instead, may reflect slow learning processes or peso problems. This is because the period under consideration is, as mentioned before atypical in terms of the prevalent exchange rate regime in the countries under analysis, and in terms of the evolution of the international value of the US dollar, which has exhibited important swings. One implication of these results is that the systematic forecast errors observed in Brazil and Uruguay suggests a substantial level of uncertainty with respect to exchange rate movements.

A rather intuitive conclusion can be drawn from this analysis. As long as what it takes to predict well is rather simple, agents perform well, but once the exchange rate determination model becomes intricate or unfamiliar, agents fail to predict.

\section{References}

1. Frankel J, Poonawala J (2010) The forward market in emerging currencies: less biased than in major currencies. J Int Money Financ 29: 585-598.

2. Bansal R, Dahlquist $M(2000)$ The forward premium puzzle: different tales from developed and emerging economies. J Int Econ 51: 115-144. 
Citation: Varela G (2014) Exchange Rate Expectations, Unbiasedness and Central Bank Intervention: The Experience of the Southern Cone. J Glob Econ 2: 110. doi:10.4172/2375-4389.1000110

Page 6 of 6

3. Gilmore S, Hayashi F (2008) Emerging market currency excess returns. NBER Working Paper 14528.

4. Calvo GA, Reinhart CM (2000) Fear of Floating. NBER Working Paper 7993

5. Pires de Souza $F(2006)$ Os regimes cambiais no Mercosul e a integracao.

6. MacDonald R (2000) Expectations formation and risk in three financial markets: surveying what the surveys say. J Econ Surv 14: 69-100.

7. Jongen R, Verschoor WFC, Wolff CCP (2008) Foreign exchange rate expectations: Survey and Synthesis. J Econ Surv 22: 140-165.
8. Zellner A (1962) An efficient method of estimating seemingly unrelated regressions and tests for aggregation bias. J Am Stat Assoc 57: 348-368.

9. Green WH (2002) Econometric Analysis. Prentice Hall.

10. Newey WK, West KD (1987) A simple, positive semi-definite, heteroskedasticity and autocorrelation consistent covariance matrix. Econometrica 55: 703-708. 